\title{
The EGP class scheme: in search of a theory
}

\author{
Jacek Tittenbrun \\ Chair of History of Sociology, Department of Sociology, Faculty of Social Sciences, \\ Adam Mickiewicz University, Wieniawskiego 1, Poznań, Poland \\ Telephone: +48612977510 \\ E-mail address: jacek@amu.edu.pl
}

\begin{abstract}
The present paper engages polemically perhaps the most popular class typology developed by John Goldthorpe and his associates. It is commonly believed that this model, as grounded in employement relations, is economic in character, and thus opposed to an alternative way of conceptualising class based on cultural considerations. It is demonstrated in the paper that whilst the above-mentioned attribution of the class scheme under consideration may be true, it is nevertheless too narrow to the extent that the framework concerned lacks a genuinely socio-economic character, or conceives it one-sidedly. As the paper shows, most, if not all drawbacks of the class taxonomy under consideration stems from neglecting a key dimension to the economy, and at the same time- its interface with society, that is to say, property relations that are only marginally taken consideration of in the EGP scheme. Consequently, the EGP class typology is found wanting in that it confounds classes of very different socio-economic or property status. These shortcomings generate controversies, one of which, related to the supposed unity of the service or middle class is examined in detail. By contrast, it is shown in the paper that it is only through rendering ownership the basic building block through to build the overall map of social differentiation that an adequate and relatively accurate picture of basic societal divisions can be painted. This concerns not only economic ownership, but also non-economic ownership as a criterion for determining the position in the extra-economic domain of society occupied by the social estates.
\end{abstract}

Keywords: the EGP class typology; Erikson; Goldthorpe; Portocarero

\section{INTRODUCTION}

The near-monopoly position enjoyed by the class taxonomy developed by John Goldthorpe and a couple of his associates prompts an examination of how it stands up to theoretical scrutiny, an important caveat being that one relatively brief article cannot do justice to the huge body of empirical research inspired by the aforementioned typology. Here, the focus is on the theoretical side of the equation.

\section{TINA}

To borrow the well-known slogan of neo-liberalism: "There Is No Alternative", which as applied to our case, can be interpreted to mean-there is no alternative economic class framework. 
Now the EGP class scheme is known alternatively as the "employment aggregate" approach. It was christened by this name by Crompton (1993), apparently on the grounds that it defines class in terms of economic position in the occupational division of labour.

In another wording of that point, "a broadly materialist (or economic) account of class reproduction would suggest that the major explanation of class inequalities rests in the nature of access to and take-up of material resources and the institutions that govern such access - for example, higher education (e.g. Goldthorpe, 2000 chapter 9).

"In capitalist societies, the majority of the population relies, directly or indirectly, on paid employment of some kind. By the late nineteenth and early twentieth centuries the occupational order began to emerge as a useful axis of classification that gave a summary indication of standard of life as well as 'life chances'. The convention developed of describing the different occupational groupings created by the application of classificatory schemes as social 'classes'" (Savage et al., 2005: 43).

First and formost, there is a serious mismatch between social classes and the technical division of labour on which the former purportedly are based.Little solace that the EGP approach, as aggregating occupations is by far better than one in which the boundary line between occupations and class is obliterated in that Grusky and Sorensen (1998) extend the approach of identifying homogeneous groupings to its ultimate conclusion arguing that unit occupations form the appropriate classEven the above observation suggests that the economic title claimed by the EGP scheme is definitely over the top, also and above all because contrary to the above-mentioned slogan, there is an alternative genuneily socio-economic approach to class, its frame of reference consisting of property relations. Moreover, and contrary to what is commonly assumed, the aformentioned alternative nature of approach under consideration does not imply any exceptive relation between it and the EGP scheme. This is because ownership refers not only to the means of economic activity (commonly narrowed down to the means of production), but also to labour power by virtue of which ownership, and consequently class relations overlap employment relations.

Meanwhile, when the former are left out of the picture, "employment-aggregate" analysis comes to be identified with the economic approach to class, if not with the class theory in general (Crompton 1998; Savage 2000; Scott 2001). Such misunderstandings tend to feed on themselves.

And indeed, critics began to argue that too great a priority has been given to economic relations in explanations of stratification, that the 'economic' cannot be rigidly demarcated as an independent factor determining stratification position, since it is inextricably intertwined with social and cultural factors. These charges all relate to the conceptual separation class analysis makes between, on the one hand, economic (as commonly believed) relations as underlying causal structures and, on the other hand, subjective and cultural identity as causal 'effects'. It has been argued that what is required is a 'closer investigation of interests and identities' (Crompton and Scott, 2000:5) to give issues of status, culture and identity a more prominent place within class analysis.

This does not mean, though, that those charges have not been retorted. Leaving at the moment aside the question of how the economic and the social are here understood, those attacked insisted on this distinction between the economic and the social because 'class concepts must be as sharply defined as is operationally feasible, in order to avoid any confounding of class with other factors of possible relevance' (Goldthorpe and Marshall 1992: 385). In practice, this means that the class structure is defined quite independently of the education, status, prestige, lifestyle, gender or ethnic composition of occupations, even though these factors are acknowledged to affect an occupation's overall position in the stratification order. Arguing that 
there is a major difference between class formation and the construction of class scheme, the said approach first defines class in terms of 'objective', external criteria and only then explores subjective meanings as a class 'effect'.

This whole debate, again, involves several misunderstandings. For one, some of the criticisms mentioned above stem from the conflation of stratification which is by definition a hierarchy with the concept of class structure whose units are interrelated in a more complex fashion.

Secondly, the defensive argument according to which one must first define what class is, and only then investigate its relationships with other, non-economic phenomena is sound; indeed, without such a definition any examination of the said relationships is impossible. And defining a class in economic terms is the hallmark of class theories; it was obvious both for Marx and Weber, two founding fathers of modern studies of social differentiation. Finally, it is odd to distinguish the social from the economic, as if economic relations were not by definition social relations, as relationships between individuals as members of a given society. Why should prestige, etc. be regarded as more social than the economy?

Furthermore, the whole talk of so-called "subjective meaning" is based on a misunderstanding. What can be viewed as a possible, albeit not inevitable effect of class relations is class consciousness as a collective phenomenon. At the same time, class members, of course, as human beings, possess each her individual consciousness whose relation to the collective class consciousness must be separately examined and not assumed a priori. Class members may be or may be not aware of their objective class position which by no means makes them either members or non-members of a given class.

\section{THE EGP AND WEBERIAN APPROACH}

Despite all those assaults on the part of individualistic, subjectivist and culturalist theorists, "studies of class and class situation have generally operated with occupational classification schemes, classifying occupations by their employment relations.

They have generally failed to focus on the property relations that are also involved in class situations" (Scott 2010).

This insight is in line with our own observations, and will be explored further below, but before proceeding it should be pointed out that the ommission concerned is odd given the common characterisation of the approach concerned; Weber, after all, was concerned with economic property relations as much as Marx was.An the point is Goldthorpe's approach is generally regarded as Weberian.

Indeed, as the following account (Scott 2010) recalls: "His earlier theoretical framework centred on a distinction between class situation and status situation as the two key dimensions of social stratification. For Goldthorpe, class and status divisions comprise the causal determinants of life chances, and social strata or social classes are seen as demographically formed groupings of individuals with similar causal determinants operating to shape their life Chances. Goldthorpe's work proposes that social stratification can, therefore, be mapped as a hierarchical structure of social classes".

There are several problems with the above account, engendered by Goldthorpe's scheme and/or Scott's comments.

To begin with, it would be better if scholars wanting to draw on other people's ideas, bother to acquaint themselves with original texts. A second-hand knowledge not everywhere works, and in science certainly does not work. What we mean here is Goldthorpe's 
misrepresentation of what he terms Weber's conception of status. The term "Soziale Stünde", which figures prominently in Weber's theory of social differentiation is, as a rule, translated into English erroneuously, as "status groups", or even "status classes". The resistance to the term "social estate" (which is how the term should be translated) is made credible by restricting the latter's applicability to such former historical epochs as feudalism whereas both for Weber and from the perspective adopted in this paper the concept of social estate has potentially a universal relevance.

Considering the relationship of Goldthorpe to Weber, it is worth mentioning that rather unexpectedly Goldthorpe's recent work has taken a cultural turn, taking up the importance of culture alongside the material facts of class situation. This has been pursued through a move from class analysis to the investigation of status. Working with Tak Wing Chan, Goldthorpe has thus of late argued for a recognition of the importance of Weber's distinction between class and status, which had been central to his own work of the 1960s (Chan and Goldthorpe 2007). Goldthorpe now uses the idea of status and the status order to explore issues of cultural consumption. Oddly enough, Goldthorpe had, at the Lockwood retirement conference at Essex, criticized those who constantly went back to Weber and his conceptual distinctions, yet his recent work not only draws such distinctions but also argues that they have been ignored or underemphasized by other sociologists.

\section{LIP SERVICE}

In actual fact, Goldthorpe et al. pay a fourfold lip service -to the notion of property, their "service class" and class approach in general, as well as to theory, or theoretical status that ought to pertain to their scheme (as Goldthorpe himself entirely agrees-cf. e.g. [1996; 2010 ]).

Thus, reverting to the above-cited passage, another common error is certainly in need of correction. Neither class nor estate theory depicts any hierarchical picture of social differentiation; this applies only to social stratification theory proper, but definitely nmot in the Weberian sense of estate, or, as Goldthorpe would have it, status (which is a misleading term insofar as it fits much better in the stratification than class framework).

To turn to the main subject of this paper, because of its complex genealogy it is variously referred to in the literature as the Goldthorpe, Erikson-Goldthorpe, EGP (Erikson-GoldthorpePortocarero) typology.

Essentially it focuses on the employment conditions of three major formations -the salariat (or service class), the petty bourgeoisie and the working class. The salariat hold relatively secure positions, often with career structures, promotion prospects and extensive fringe benefits. The working class have less secure positions, higher risks of unemployment, fewer benefits and are subject to a more restrictive labour contract. In contrast to both these formations, the petty bourgeoisie are directly exposed to market forces without the protection of salaried employment or trade union organisation. In between these three groupings, Erikson et al. place the routine non-manual class, which is in a sense marginal to the salariat proper and shares only some of its advantages, and the foremen/technician class, which is marginal to (and somewhat more advantaged than) the working class proper.

It is argued that this class scheme is only partially hierarchical, which if true leaves it in limbo, for this kind of ordering is characteristic of stratification systems.

Those who support such a view, indicate that While the salariat is generally more advantaged than the other five classes and the semi-skilled and unskilled working class is more disadvantaged, the other classes (III, IV, V and VI) cannot easily be placed in a hierarchical 
relation to one another. They have essentially different employment relations and somewhat diverse packages of remuneration and benefit.

The matter is not that simple, however. After all, the principal creator of the framework concerned has raised the question whether, "instead of adopting the 'typological' approach that is implicit in the scheme, would it not be better to think of the service relationship and the labour contract as simply marking the theoretical limits of what is in fact a continuum [emphasis in the original] of forms of employment regulation?" (Goldthorpe 1997: 42). Significantly, the choice between class or continuum is taken to be essentially an empirical and not a theoretical matter; his response to his own question was that 'in the British case, at all events, the typological approach would seem empirically vindicated', in that the various defining criteria appear to form into distinct groupings that suggest homogeneous classes with distinct boundaries. This might suggest that in some other empirical context it could be otherwise.

Even at this point of presentation, a few comments regarding specific class labels used can be made. The doubly named service class owes its title probably to its supposed connection to civil servants rather than ordinary service providers(which, though, hav an advantage of being economic agents, as distinct from the former), such as hairdressers. On the other hand, one rightly speaks of legal or medical services, and the sheer number of diverse terms applicable in the context in question does not bode well for the consistency and cohesion of the overall scheme, which will be explored further below.

Another key concept in the said framework is equally ambiguous. Besides, the term "working class" has a long history behind it, so that its cavalier treatment is striking. More importantly, the term has in many European languages at least dual connotation, stemming, inter alia, from the overlaps between such concepts as "work" and "labour". The crux of the matter is, "worker" can be also rendered as "employee", and in a number of European languages there is also an equivalent equivocation, giving rise to the potentially alternative term of employee class. In later sections it will be seen that Goldthorpe's (to use his name as a proxy) unawareness of this duality coupled with the technical, instead of socio-economic, understanding of class criteria lies at the root of key problems plaguing the theory.

The above-mentioned relative neglect of property relations manifests itself in an elaboration of the basic classification laid out above.

In an extended version of the typology, Erikson and Goldthorpe subdivide the classes IV and VII distinguishing farmers and farm managers (class IVc) from other employers (IVa) and own-account workers (IVb). They also distinguish farm labourers (VIIb) from other low-skilled workers (VIIa).

Goldthorpe (1987). Goldthorpe has argued that the privileged section of property holders can be regarded as an 'elite' within the 'service class'. A service class, for Goldthorpe, is defined by the employment relations of its members, and its especially privileged members are, for Goldthorpe, those who additionally have propertied interests.

This makes it clear that the main problem with the scheme may lie not as much in the outright rejection as in the authors' misapprehension of what property actually is. Otherwise, the scheme would generate something like a "propertied class" instead of subsuming its members into another category whose very name scarcely fits the nature of their economic activities, as merely a fraction operates in the services sector.

Anyway, the resulting class map can be sketched out as follows. There is one class of the self-employed and small employers (petty-bourgeoisie), labeled class IV (the classification uses Roman numerals). This is subdivided first on a sectoral basis, so that IVc comprises farmers and 'other self-employed workers in primary production', and secondly between non- 
agricultural employers and the self-employed: IVa comprises small proprietors with employees 4 , IVb those without employees. The remaining classes are comprised of employee positions, distinguished on the basis of their employment relations. Classes I and II are made up of those occupations that most clearly have a service relationship: the distinction between them is a matter of degree. So class I comprises higher grade, and class II lower grade, professionals, higher technical, administrative and managerial workers. At the other extreme, members of classes VI (skilled manual workers) and VII (unskilled manual workers) most clearly have a labour contract with their employer. Class VII is itself also divided sectorally: VIIb is non-skilled agricultural workers, VIIa is non-skilled workers outside agriculture.

The remaining classes, III (routine nonmanual occupations) and V (lower technical and manual supervisory occupations), 'comprise positions with associated employment relationships that would appear characteristically to take on a very mixed form' (Erikson and Goldthorpe 1992: 43).

What is strikingly absent from the scheme is a class of large employers - the haute bourgeoisie. Nowadays large employers tend to be organisations rather than individuals, but those individual large employers that exist are placed in class I. Erikson and Goldthorpe (1992: 40-1) justify this practice on the grounds that such individuals are usually owners of enterprises that differ from those of the petty bourgeoisie in legal rather than substantive terms. They are placed in class I rather than IV because 'in so far as such large proprietors tend to be quite extensively involved in managerial as well as entrepreneurial activities, they may be regarded as having a yet greater affinity with those salaried managers to be found in class I who have a substantial share in the ownership of the enterprises in which they work'.

The last point is well taken, as opposed to those preceding it.Enterprises held by "large proprietors or employers" cannot be compared to those run by the petty-bourgeoisie for one simple reason-one may agree indeed that the legal form as such is irrelevant, but this does not erase the fundamental distinction between the respective ownership, and thereby class relationsout of the two, it is only the capitalist class that employs the labour power of others. In addition, if the above-mentioned term of Goldthorpe is taken to mean large capitalists, which seems to be a legitimate conclusion, then their presumably distinctive characteristics by any means fit this title. First, Large owners rarely, if at all, engage in day-to-day management. But then the matter comes to be complicated still further.

The reader is told that large proprietors or employers account for 'around 5 per cent of all men $^{1}$ allocated to the service class (i.e. Classes I and II) in Western industrial societies, and cannot ... be realistically seen as members of a capitalist elite ... Rather, they turn out on examination to be most typically the owners of stores, hotels, restaurants, garages, small factories or transportation firms' (Goldthorpe 1990: 435).

If the above is to be taken seriously, this would mean that the scheme in question captures just the small capitalist class, as a critterion of which personal work or management of one's own property in the form of an industrial, transportation, etc. firm may be given. It still leaves out of the picture the big bourgeoisie, including the rentier class who may be engaged in philanthropy, politics or whatever, leaving the economy to others.

Anyway, the resulting class scheme gives rise to seven major classes. Its finest disaggregation is an 11-category version (which includes, aside from those already mentioned, a distinction between classes IIIa and IIIb, higher- and lower-grade routine non-manual workers6), while the most aggregated version that nevertheless would seem to preserve the

\footnotetext{
${ }^{1}$ Thus in original, which accounts in part for criticisms levied against the EGP approach by many feminist scholars.
} 
essential distinctions of the scheme is probably a four-category classification of the service (I and II), intermediate (III and V), petty-bourgeois (IV) and labour contract (VI and VII) classes.

Goldthope's persistent recourse to such concepts as "manual", non-manual" and the like as the chief descriptors within his framework corroborates that he cannot move beyond the confines of technical division of work.

Considering another aspect of our headline, although it might seem that positions are put into classes according to their relationship to the means of production and then to the kind of employment relationship they display, in fact the EGP scheme is not operationalized by measuring these characteristics of positions and assigning them to classes on this basis. Instead, occupations are assigned to classes on the basis of their employment relations.

Now, referring back to another of our headline issues, that of scientific quality pertaining to the scheme, because the type of employment relationship (recall, underlying class relations ) is defined by a number of different features (salary increments, pension rights and assurances of security are among features of the service relationship listed by the authors), the question arises of the extent to which they do in fact occur together within occupations. If, e.g., these aspects of employment relationships were only weakly related to one another this would call into question the operationalization of the concepts of classes, as the latter are defined by those now found out to be incoherent-relationships.

And indeed, Evans and Mills (2000: 657) found out that the operationalization of the scheme presents some problems.

The majority of Goldthorpe's class II do not have a 'service' type of employment contract. The dividing line between the service and the intermediate classes appears to run through class II rather than between class II and class IIIa. They also estimate that about a third of class I employees do not have a 'service' contract.

Apart from substantive issues, this calls into question the methodological grounds for the practice of relying wholly on occupational titles as the basis of the empirical classification This is at least the second moment, along with the apparent ignorance of ways of the big bourgeoisie, that the sociological celebrity in question shows in fact a glaring lack of robust knowledge, and additionally in this instance, weak competence by virtue of which to eliminate those gaps through credible investigation. But credible it is not. Just one example, in our times in terms of occupational titles, managers of various sorts abound-there are "product managers", "account managers", "project managers", and so on, but in reality only few of those who bear these proud titles perform genuinely executive work. This, though, can be established only upon empirical investigation on the spot, which has little in common with just reading business cards.

But let us give Goldthorpe et al. the benefit of the doubt and see whether further features of their approachcan justify their claim to the virtual monopoly of stratification/class (as this issue has been left open) research.

The EGP class scheme "concentrates on payment conditions as central to the labour/service contract distinction. This means that their analysis, which results in the specific identification of only the three basic classes, is actually based on just four items: (1) whether paid hourly, by salary or by salary plus commission etc; (2) whether or not paid for overtime (or given time off in lieu); (3) having to give less than four weeks notice or four weeks or more; and (4) whether they or their employer decides the times of starting and finishing work" (Prandy 2002).

The problem is, it is not known why these particular traits have been chosen rather than some others. A corresponding charge has been made to the effect that a categorial distinction between one social class and another, is based it seems, as John Scott says, on little more than the 'informed professional judgement' of the researcher (Scott 1996: 131) and irrespective of 
however arbitrary the resulting boundary line might seem to be. It is exactly for that reason that Sorensen can voice his criticism: "While Goldthorpe identifies market, employment relations, and authority as the bases for the scheme, the precise link between these defining relationships and the actual scheme is not specified" (2000). This in turn results from the specific nature of the scheme. It is primarily empiricist, and undertheorised. Goldthorpe, to be sure, reacted with irritation to a related "supposition (Pahl 1993) that Marshall and I would conceive of class analysis as being entirely atheoretical!" (2010).

And yet this anger has not prevented Crompton's harsh indictment: "Goldthorpe's materialist account is criticised as being descriptive and tautological, advantages are generated through being in a position of advantage, and the advantaged middle classes always win" (Crompton 2006).

\section{THE MISSING LINK}

Arguably, the theoretical underpinning missing in the EGP taxonomy could be provided by the notion of ownership of labour power on the basis of which one can distinguish and put within a theoretical framework a veriety of types of labour power such as ascriptive vs. achievement-oriented labour power and many others which for reasons of space are not discussed here. Similarly, what is missing in the EGP class scheme is the notion of ownership of jobs, in fact to be found in Weber's work whose cognitive appropriation, so to speak, on the part of Goldthorpe appears to be rather superficial, to say the least.

More broadly, it can be argued that "a key problem in Goldthorpe's approach is that while the role of property divisions has been recognized, it has been treated as a largely residual factor" (Scott 2010).

It is not only that the role of property relations is sidelined, but Goldthorpe's reference to them is largely problematic. For it is misleading to consider on the same footing the autocephalous class (the term borrowed from Weber) or, in a more plain language, the category of self-employed and the employee classes. There is a fundamental class division between those who own the means of economic activity and the owners of sole labour power. Even more inadmissible, of course, is the inclusion of the propertied classes along with the employee classes in one common category, as a version of the EGP scheme would have it. The scheme recognises the class distinctiveness of managers and formen, but does not command any theoretical resources to pin down their proper class position. The same refers to technicians who, for some unstated reason, are classified together with formen, although, upon scrutiny, many of them, like engineers, would assuredly belong to the conceptual class, as the category of producers of the intellectual means of work or performers of pre-material work can be termed.

Although the class affinity of top managers and capitalists indeed exists, to reduce the distinction between the latter and the autocephalous class to a legal one amounts to the manifestation of the lack of a socio-economic perspective. Meanwhile, to benefit from other people's labour power is naturally a socio-economic, ownership characteristic. 


\section{THE SERVICE CLASS-ONE OR MANY?}

The EGP scheme being that under-theorised, it is no wonder that it leaves a great many problems unresolved, which not only are pinpointed by the critics, but give rise to hot debates amongst the adherents of given approach.

Viewing the service class - Classes I and II in the EGP scheme (Erikson and Goldthorpe 1992: 37-41) - as a class of professional, managerial, and administrative employees, Goldthorpe (1995: 314-315) argues what demarcates the service class from other employee classes is a distinctive employment relationship: a service relationship. By contrast,Savage et al. put forward an alternative view that there are at least three middle classes - namely, the entrepreneurial, professional, and managerial - differentiated by their respective command of property assets (economic assets), cultural assets (credentials, skills, or expertise), and organisational assets (positions in an organisation) in the course of their careers. (Wong 2004)

The above-mentioned split is significant in that it recognises that the class situation of the respective categories is different from one another however controversial the basis of their distinction would appear (again, the concept of ownership of labour power is absent although it is badly needed).

But it is much more to the matter than that. Leaving out a tricky question of class position pertinent to "enterpreneurs", 2 it can be argued that As far as employees are concerned, the debate is over whether the service class is unified or is divided between professionals and managers.

Goldthorpe maintains that the differences between them are fairly small and are of an intra-class rather than an inter-class kind.

Simplifications of this view are not hard to see, so it is not surprising that challenging Goldthorpe's position, Savage et al. claim that professionals and managers are two middle classes following two distinct career patterns. In order to get into their respective fields and then to advance further, professionals have to rely more on cultural assets and managers organisational assets.

Cultural assets are objectified in credentials, embodied in the habitus, and transferable from one context to another, and are therefore readily stored and transmitted, whereas organisational assets are context-specific and non-transferable, and are thus difficult to be transmitted. As a result, professionals are much better able to secure their advantages throughout their worklives vis-à-vis managers; and managers are likely to seek selfemployment as a main career strategy to counteract their insecurity. Besides, resulting from their dissimilar career experiences, professionals and managers may develop different aspirations and thus strategies for their children; professionals are simply much better able to secure their advantages over generations vis-à-vis managers.

Consequently, professionals will become a stable and cohesive middle class, whereas managers will turn into an insecure and marginalized middle class.

So, instead of expecting a mature unified service class, Savage et al. (1992: 216-217) predict that the service class is moving towards a deepening of the split between professional and management (Wong 2004).

First, a brief terminological comment-relevant inasmuch as it connects to one of the potential misnomers hiding behind the framework under consideration; the concept of middle class, very much in use in the EGP camp, comes, its core noun notwithstanding, from the

\footnotetext{
${ }^{2}$ This is because in most cases, including the present one, it is a misnomer. According to Schumpeter' classic definition, by no means every owner of a business, or corporate executive becomes ipso facto an entepreneur.
} 
stratification imagery, as in turn the adjective, pointing clearly to its hierarchical nature, suggest.

As to the key point made above, again, should the critic of Goldthorpe commanded the notion of labour power, he would be much more cautious in claiming what he had claimed. Managers are of course not ascribed to their employing firms in the likeness of feudal serfs ascribed to land. On the contrary, their high-grade labour power embodying high managerial skills enables them to move from one organisation to the next with relative ease. It is evident that the author/s of the claim to the contrary are not familiar with the intricacies of the executive labour power market. Lacking such familiarity, though, to engage in a debate over the class location of capitalist execcutives seems an extremely risky, if not futile enterprise.

Given how shaky the theoretical and empirical foundations of the dispute concerned are, it was certain that new arguments will appear.And indeed one researcher has addressed the issue of whether "a unified middle class or two middle classes - professionals and managers - are formed and reproduced" (Wong 2004). The researcher in question has compared] the career strategies and intergenerational mobility strategies of managers and teachers (a professional group).

The selection of this comparison base reveals again the extent of confusion present in the analytical framework of neo-Weberians, as often (definitely over the top ) Goldthorpe and his numerous followers are dubbed. teachers generally, exclusive of those who are employed in privately owned, oriented on profit educational establishments, do not belong to any socioeconomic class, so the dispute should have been resolved even before its beginning. Nevertheless, the research went its course, taking for granted that the "professional group" in question is also a class. Despite this flaw, it is worthwhile to discuss at least some of the results of the study, notably with an eye to the question of consistency and other prerequisites of scientific theory.

At the very outset, the theoretical worth of Wong's, and by extension-Goldthorpe's analytical tools, is called into question. Wong, according to his own words, "did not choose a managerial group of a specific rank or working in a particular kind of sector or field or organisation. Rather, I included managers or administrators of a higher grade (Class I) or of a lower grade (Class II), working in the private or the public sector, in a large corporation or a small firm, in a local company or an international organisation (Wong 2004).

Now this framing of "managerial group" is untenable; it comprises both corporate executives and administrators of public institutions, lumping thereby together social estates(groups grounded in the non-economic property relations ) and socio-economic classes. Therefore, all the following exposition and especially its conclusions should be read with a pinch of theoretical salt. All the more that the analoguous error is repeated with respect to the next group of Wong's respondents: "In recruiting teachers, I included those working in a private or public teaching institution, not only from Class I - instructors or lecturers in tertiary institutes or universities - but also from Class II - teachers in primary or secondary schools" (2004).

What is significant for our purposes, is not only this blurring of a key ownership divide and resulting implications for Wong's sample, but the fact that in making those errors he has drawn on Goldthorpe's typology.

Wong turns then to "how teachers and managers made their ways into their professions. It turns out that there are striking differences with regard to how teachers and managers get their respective jobs.

"The formal qualifications of teachers are in general higher than those of managers. Most teachers hold either a diploma or a degree whereas a few managers had not completed form five at secondary level. One possible reason for this $[\ldots]$ is that entry requirements for teachers 
are rather strict, which is not the case for managers[...] By contrast, no such requirements are necessary for getting a managerial post" (Wong 2004).

This difference is nicely captured by our distinction between formal(manifested by official credentials) and real (in which actual skills are pivotal) labour power, the latter predominating among the managers investigated by Wong.

Turning to his further findings, again highlighting the disparity rather than convergence between the two prospective classes, Wong introduces some presumably theoretical concepts: "This occupational difference is further reflected in two routes for those teachers who entered the teaching profession at a later stage. They were able to obtain a teaching job either because they had already had the required qualification [...] or because they had obtained the required qualification [...] through further studies. In short, if cultural assets in terms of qualifications are regarded as absolutely crucial in leading both teachers and managers straight into their professions, then cultural assets could well be considered to be far more important for a teaching job than for a managerial one" (2004).

The concept of cultural assets or, still worse, cultural capital, is misleading, or, more precisely, a misnomer. The said concept and the array of its clons are subject to the criticism by Baron and Hannan (1994: 1124) who are "baffled that sociologists have begun referring to virtually every social feature as a form of capital". Besides, regarding specifically the abovementioned term, one can object to its specific designation; why should business qualifications be classified as cultural rather than economic in nature? The genesis is here conflated with function or realisation; the fact that the given qualifications are acquired through education does not make them educational in nature; part of such skills can well be acquired during the primitive socialisation. But does it follow that they are to be classed as familial?

Our characterisation of managers as holders of real labour power is implicitly expanded on below: "most managerial jobs require an individual to have not only a relatively high level of maturity but also a certain level of management ability and a familiarity with a given profession, so that the individual is able to manage the daily operation of even a small division of a company. A relatively high formal qualification is not necessarily a good substitute for relevant management experiences in a given profession. This is reflected in the two routes for those managers who took up a managerial post at a later stage - those coming to it via a professional first job and those undertaking further studies. With a higher qualification, these managers still had to work their way up in their organisations gaining enough experience and seniority in their fields so as to get promoted to their first managerial posts. We can say that their being able to take up a managerial post results from their command of organisational assets rather than cultural assets" (Wong 2004).

This is a logical fallacy of petitio principii in which what is to be proven is assumed in the premise. In other words, the existence of "organisational assets" has been taken for granted, as if their very existence and the content of the concept were self-evident, not requiring demonstration. We contend, again, that the relationship concerned is much better rendered by the concept of real labour power.

Wong adds further specifics, validating even further the above-mentioned distinction between real and formal labour power: "Because no strict entry requirements are applied to this profession, it is even possible to become a manager through what could be thought of as a more 'unusual' way.[...] four managers became managers by having been employers in small companies. Completing only a primary education, these four managers started as manual workers and, despite this disadvantageous career start, they exploited their work experiences, work contacts, and capital in the course of their working lives and eventually took up a 
managerial post after setting up a small company with a group of business partners" (Wong 2004).

Again implicitly in terms of labour power, but on the surface in a very different language, Wong reports: "With a required teaching qualification, teachers could have changed to teach in any institution and applied for a senior teaching post even in a different institution" (2004).

At last, our earlier point has been vindicated; we have contended that teachers and professionals in general hold fairly general- as opposed to specific-labour power, which can be moved between many different jobs.

As to the concept of "organisational assets" which is, to be sure, somewhat better than "organisational capital", we reject it as doubling, as the notion of seniority clearly highlights, ascriptive characteristics of labour power. This very dimension of labour power is crucial in the case of managers, as Wong's following account shows: "A considerable number of managers had worked in the same organisations; they followed a clearly established career path, which is usually much longer than that followed by teachers, in the same organisations and got promoted to different managerial posts. Their subsequent promotions can be viewed as resulting solely from their command of organisational assets.[...] companies are willing to support managers' acquisition of organisational power by offering the prospect of quite long careers to their managers" (2004).

Leaving out the remaining results of the study, let us turn immediately to itss implications for the initial proposition outlining two alternative models of the service class. Wong sums up his findings: "My data [...] support Savage et al.'s claim that managerial and professional groups are rather different. [...] teachers drew exclusively on cultural assets whereas managers relied more on organisational assets than on cultural assets".

So far, so clear, at least as far as the settlement of the debate over the service class is concerned.Yet, whilst already the initial assumptions have been flawed, these failings have been multiplied as a result of the study whose rationale has been to settle the controversy in question. This is manifested in additional terms that from the scientific point of view contribute no theoretical added value. It is this obfuscating rather than clarifying reality analytical framework that can confuse even the above straightforward assertion:

Yet, apart from commanding organisational assets, some managers had to draw on cultural assets [...] the subsequent promotions of some managers, like those of some teachers, are directly related to their command of cultural assets in terms of a higher qualification obtained at a later stage. This supports the suggestion that modern management is becoming increasingly professionalized. Seniority and experience developed in the same field or organisation is not enough for good management: managers need to equip themselves with more updated professional knowledge and skills in management.[...]

It is true that in the course of their worklives teachers drew more on cultural assets while managers relied more on organisational assets. Nevertheless, most teachers and managers had to utilize cultural and organisational assets simultaneously, which are usually mutually reinforcing, to an extent that the command of cultural assets and the command of organisational assets are equally crucial to their subsequent advancement. Exploiting cultural assets in a particular organisation enables them to develop organisational assets, while mobilizing organisational assets enables them to develop cultural assets. [...] In this sense, [...] the career strategies and career patterns of teachers and managers are not so distinct as Savage et al. would have us believe, and [...] their differences could be regarded as of an intra-class rather than of an inter-class kind, as Goldthorpe argues. (Wong 2004)

What is particularly relevant to the debate is that the Chinese sociologist becomes so entangled in his (borrowed from Bourdieu) language that he falls prey to the false dialectic, 
manifested in his ping-pong arguments whereby one type of his "assets" breeds another one, and vice versa, the upshot being a kind of vicious circle, most difficult to disentangle.

Meanwhile, as suggested above, from an alternative perspective formal credentials, actual skills, experience and other features mentioned above are part and parcel of labour power. The other side of the coin is that a variety of assets multiplied by the writer concerned are useless fictions or misnomers.

As the study under consideration includes yet another distinct set of findings, let us give the author the benefit of the doubt, again limiting our attention to the quintessence of his results. Wong himself puts what is his second major finding as follows: "More teachers than managers took extensive advice on their children's subject choices and got their children into the school of their choice. Nevertheless, in promoting their children's educational success, managers did not seem less able than teachers to use their economic, cultural, and social resources" (Wong 2004).

As suggested above, teachers are a social estate. Accordingly, their command of social connections, as included among the relations of non-economic ownership, is in those terms only natural.

All in all, Wong's final conclusion is unwarranted, which stems from his lack of analytical tools sensitive enough to pin down the essential division between the socio-economic classes and social estates as well as to adequately specify the peculiarities of the social position of the categories concerned, which, we surmise, is difficult, if not impossible, without a conception of ownership of labour power. Wong reckons, namely, that "the comparisons of the career strategies and intergenerational mobility strategies of teachers and managers give more support to Goldthorpe's view than to Savage et al.'s. Savage et al. are right in that teachers and managers are rather different in their approach to entering their respective professions. Teachers had to draw exclusively on cultural assets whereas managers relied considerably on organisational assets (Wong 2004)".

How come? Having put evidence on back burner, the entire array of elusive assets can be manipulated as one sees fit Accordingly, Wong argues: "However, teachers and managers are alike in that in order to advance further they both had to use cultural and organisational assets simultaneously to such an extent that neither kind of asset seemed less crucial to their subsequent promotions. Despite their somewhat different career strategies and patterns, managers did not seem less able than teachers to secure their advantages through their worklives" (Wong 2004).

Both the above and following passage teem with imprecise claims and ambiguous concepts, such as alike, the same, etc. The basis and criteria for such comparisons are unstated, which is, frankly, not surprising given that even strict criteria applied to this fuzzy concepts are bound to compel renouncement of any claim to anything like scientific accuracy, which leaves all the constituents, and by implication the EGP framework in toto in dire straits.

In a similar vein, Wong ends the presentation of his research findings with an assertion that can be interpreted in two ways-either as -in line with the above reasoning- a consequence of clumsy, reality-unfrendly analytical apparatus, or alternatively, as a result of cooking up explanations, handpicking the data to fit the thesis assumed in fact a priori, but misleadingly presented as an inference from the said, presumably unbiased evidence: "More importantly, both teachers and managers used the same strategy for their children in order to secure them a relatively advantaged position, enabling their children to become a professional through attaining a relatively high level of education.

In carrying out the same strategy, both teachers and managers used economic, cultural, and social resources in a similar way. [...] there are no signs to show the service class is divided 
between a stable, cohesive, professional middle class and an insecure, marginalized, managerial middle class. Instead, the comparisons indicate that a unified middle class is in the making as far as its demographic stability over generations is concerned(Wong 2004).

\section{CONCLUSION}

The final claim in the previous section merely adds to the confusion caused by the foregoing. It is only in Weber's concept of social, as opposed to economic, class that the criterion of social mobility is used, but with reference to both inter- and intra-generational movement. Besides, the point is not the division of the allegedly unified service or middle class into two subclasses endowed with very specific characteristics, but the very existence of such a unitary class, no matter what the secondary features of its subgroups may be .The multiplication of criteria for class identification scarcely contributes to the clarity and lack of ambiguity of an analytical framework. In this particular case, an attempt, probably an effect of the critique on the part of the culturalist camp, to combine the EGP approach with that of Bourdieu, as the concepts of diverse assets show, has failed. The original scheme has had its weaknesses, to which only new shortcomings have been added. The root cause of those problems seems to lie in the lack of a consistent theoretical framework that, it is proposed, can be provided by the theory of ownership, including ownership of labour power. Needless to say, the study discussed above served merely as a laboratory case, so to speak, of broader trends displayed by their parent framework. It is not enough to label one modestly as a "scheme" to avoid the charge ofunder-theorization, for each cognition of the world, each research process is entangled in a whole host of theoretical assumptions and categories. The less one is aware of this inevitable fact, the bigger chance of adopting of poor-quality crypto-theories which do more harm than good as far as research is concerned. And this precisely is the case of celebrated EGP class scheme. Its basic categories are ill-specified, which engenders fierce-and for all intents and purposes unsolvable-debates over the scope and exact meaning of particular concepts, as the above discussion exemplifies. If one were to pick the single most important reason for those theoretical problems, in this author's view it is surely the conception of socio-economic property relations (inclusive of an all-important concept of labour power), or rather-its lack.

\section{References}

[1] Baron, J. \& M. Hannan. "The Impact of Economics on Contemporary Sociology." Journal of Economic Literature 32 (1994) 1111-1146.

[2] Chan T.W. and Goldthorpe J.H., Class and Status: The Conceptual Distinction and its Empirical Relevance', American Sociological Review 72 (2007) 512-532.

[3] Chan T.W., Goldthorpe J.H., Social Status and Newspaper Readership', American Journal of Sociology 1124 (2007) 1095-1134.

[4] Crompton R., Scott J. (2005). 'Class analysis, beyond the cultural turn' in Devine, F., Savage, M., Scott, J. and Crompton, R., Rethinking Class, Palgrave Macmillan:

Basingstoke. 
[5] Crompton R. (1993; 1998). Class and Stratification, Polity: Cambridge. Crompton, R. 2006. Employment and the Family: the Reconfiguration of Work and Family Life in Contemporary Societies, Cambridge University Press: Cambridge.

[6] Erikson, R. and Goldthorpe, J. (1992). The Constant Flux: A Study of Class Mobility in Industrial Societies, Oxford: Clarendon Press.

[7] Erikson R., Jonsson J.O. (1993). Ursprung och Utbildning, Stockholm: Statens Offentliga Utredningar.

[8] Evans Jeffrey and Colin Mills December. In search of the wage-labour /service contract: new evidence on the validity of the Goldthorpe class schema, British Journal of Sociology 51(4) (2000) 641-661.

[9] Goldthorpe J., 'Class analysis and the reorientation of class theory: the case of persisting differentials in educational attainment, British Journal of Sociology 47(3) (1996) 481-505.

[10] Goldthorpe, J. 2010. 'Class Analysis and the Reorientation of Class Theory: The Case of Persisting Differentials in Educational Attainment', The British Journal of Sociology The BJS: Shaping Sociology Over 60 Years: 311-335. [Originally published in 1996 British Journal of Sociology 473: 481-505.]

[11] Goldthorpe, J. and G. Marshall 1992. 'The Promising Future of Class Analysis: A Response to Recent Critiques', Sociology 263: 381-400.

[12] Goldthorpe, J. and Marshall, G. 1992. 'The Promising Future of Class Analysis: A Response to Recent Critiques', Sociology 263: 381-400.

[13] Goldthorpe, J.H. and Marshall, G. 1992. 'The Promising Future of Class Analysis: A Response to Recent Critiques', Sociology 26: 381-400.

[14] Grusky, David, and Jesper B. Sorensen. 1998. "Can Class Analysis Be Salvaged?" American Journal of Sociology 103:1187-1234.

[15] Pahl, R.E. 1989. 'Is the Emperor Naked?' International Journal of Urban and Regional Research 134: 709-720.

[16] Pahl, R.E. 1993. 'Does Class Analysis without Class Theory have a Promising Future? A Reply to Goldthorpe and Marshall, Sociology 27: 253-258.

[17] Prandy, K. 2002. 'Ideal types, stereotypes and classes', British Journal of Sociology 534: 583-602.

[18] Savage, M. 2000. Class Analysis and Social Transformation, Buckingham: Open University Press.

[19] Scott, J. 1996. 'Comment on Goldthorpe', British Journal of Sociology 47: 507-512.

[20] Scott J., Central concerns in social stratification research: comments on Goldthorpe, British Journal of Sociology 61(1) (2010) 337-341.

[21] Sorensen, A. 2000. 'Employment Relations and Class Structure', in Crompton, R., Devine, F., Savage, M. and Scott, J. eds. Renewing Class Analysis, Oxford: Blackwells. 
[22] Wong, Y.L. 2001. Family Strategy: A Study of Intergenerational Mobility in Hong Kong Oxford: D.Phil. Thesis, Nuffield College, University of Oxford.

[23] Wong Yi-Lee, A unified middle class or two middle classes? A comparison of career strategies and intergenerational mobility strategies between teachers and managers in contemporary Hong Kong. British Journal of Sociology 55(2) (2004).। 